Check for updates

Cite this: RSC Adv., 2017, 7, 51605

Received 17th September 2017 Accepted 31st October 2017

DOI: 10.1039/c7ra10323a

rsc.li/rsc-advances

\section{One-pot synthesis of ultrafine amphiphilic Janus gold nanoparticles by toluene/water emulsion reaction}

\author{
Kun Luo, (D) *a Chengliang Hu, ${ }^{a}$ Yujia Luo, ${ }^{\text {b }}$ Degui Li, ${ }^{a}$ Yongdong Xiang, ${ }^{a}$ Yuanying Mu, ${ }^{a}$ \\ Haiming Wang ${ }^{a}$ and Zhihong Luo ${ }^{a}$
}

\begin{abstract}
Ultrafine amphiphilic Janus gold nanoparticles (Au NPs, $d \approx 2.1 \mathrm{~nm}$ ) were synthesized in batch by the emulsion reaction between chlorotriphenylphosphine gold(I) in toluene and tetrakis(hydroxymethyl) phosphonium chloride in alkaline solution, followed with phase inversion by adding excess toluene, resulting in a yielding rate of up to $93.3 \%$. FT-IR, Raman, TG and XPS analyses indicate that the emulsion reaction product is composed of Au NPs protected by triphenylphosphine, tris(hydroxymethyl)phosphine and their oxides. A NOESY experiment indicates that these ligands are separated into hydrophilic and lipophilic compartments on the individual Au NPs. The Janus wettability of the thin films by the static toluene/water interfacial reaction and Langmuir re-assembly of the as-dispersed emulsion reaction product suggests that spontaneous phase separation of capping ligands occurs with the formation of the Au NPs at the toluene/water interface, which can be maintained even in the colloidal state. The scalable one-pot synthesis of the amphiphilic Janus Au NPs allows further functionalization for the diagnosis and therapy of cancers and biphasic catalysis at low cost.
\end{abstract}

\section{Introduction}

Gold nanoparticles (Au NPs) have been recognized as attractive candidates for the diagnosis and therapy of disease. ${ }^{\mathbf{1 - 4}}$ The absorbance and fluorescence can be tuned to the near-infrared region by altering the size and morphology of Au NPs, where body tissues absorb weakly and hence allow some optical applications in vivo, including optical imaging ${ }^{5}$ and photothermal ${ }^{6}$ or radio therapy. ${ }^{7}$ The high atomic index and electron density of Au NPs are also beneficial for the efficient absorption of X-ray radiation, which lead to a better contrast for CT and MRI than the conventional iodine-based agents. ${ }^{5,8}$ Moreover, the excellent biocompatibility, chemical stability and low toxicity allow $\mathrm{Au}$ NPs to serve as prospective targeting delivery agents into tumour cells by the effect of permeability and retention (EPR), ${ }^{9}$ where drug molecules can be released by external stimuli (such as $\mathrm{pH}^{\mathbf{1 0 , 1 1}}$ temperature, ${ }^{12}$ light $^{13}$ or competitive molecules). In this aspect, drug molecules are either covalently conjugated onto $\mathrm{Au} \mathrm{NPs},{ }^{\mathbf{1 4 - 1 6}}$ or encapsulated in Au-NP-stabilized Pickering emulsions. ${ }^{17,18}$ In the latter case, ultrafine Au NPs are used to build up nanoscale micellar vehicles, which can provide with large loading capacity and multiple drug cargos into tumour cells. For example, nanomicelles

${ }^{a}$ College of Materials Science and Engineering, Guilin University of Technology, 12 Jiangan Road, Guilin 541004, P. R. China. E-mail: luokun@glut.edu.cn

${ }^{b}$ The First Hospital of China Medical University, 155 Nanjing Street, Heping District, Shenyang 10122, P. R. China encapsulated (in size from $22 \mathrm{~nm}$ to $48 \mathrm{~nm}$ ) by amphiphilic $\mathrm{Au}$ NPs with polycaprolactone and methoxypoly(ethylene glycol) were reported to carry a model drug, 5-fluorouracil, where the drug release could last for more than 4 days. ${ }^{17,19}$

However, homogeneous nanoparticles $(d<10 \mathrm{~nm})$ normally suffer from unstable adsorption at oil/water interfaces, which rely heavily on contact angles: at $c a .0^{\circ}$ (or $180^{\circ}$ ), the desorption energy of NPs at the interface is only $1 / 3000$ of the one at $90^{\circ}$, in which case the interfacial adsorption can hardly stand thermal fluctuations. ${ }^{20}$ Research has shown that amphiphilic Janus NPs exhibit ca. 3-fold desorption energy of the homogeneous counterparts at immiscible liquid/liquid interfaces, ${ }^{21}$ which can stay at the interfaces even at a contact angle of $0^{\circ}$ (or $180^{\circ}$ ). Efforts have been paid on the interface engineering of homogeneous NPs. To avoid the possible overturn during surface modification, Pradhan et al. ${ }^{22,23}$ assembled the hexanethiolateprotected Au NPs $(d \approx 2 \mathrm{~nm})$ into a Langmuir film, which was then immersed in the 2-(2-mercapto ethoxy)ethanol solution, resulted in amphiphilic Janus Au NPs after ligand exchange in part. Xu et al. simplified the operation, ${ }^{24}$ where the precursor octanethiolate-protected Au NPs $(d \approx 5 \mathrm{~nm})$ were compressed to form a Langmuir film, but the ligand exchange was triggered by the injection of 3-mercaptopropane-1,2-diol into the water underneath without removal of the film.

Andala et $a .^{25}$ reported that the immiscible liquid/liquid interface facilitates the spontaneous phase separation between hydrophilic and hydrophobic ligands, where the ligand substitution of dodecylamine on the precursor Au NPs $(d \approx 9.2$ 
$\mathrm{nm}$ ) by mercaptoundecanoic acid and dodecanethiol at the toluene/water interface directly led to the formation of amphiphilic Janus Au NPs, no matter the thiol ligands were introduced simultaneously or one-by-one into the system, since the adsorption of amphiphilic particles localized at the interface is thermodynamically more favorable than those with mixed ligands. Inspired by the approach, a series of phosphinemodified amphiphilic Janus Au NPs ranging from $2 \mathrm{~nm}$ to $18 \mathrm{~nm}$ were synthesized by ligand exchange at toluene/water interface in our previous work. ${ }^{26}$ Moreover, Kim et al. recently demonstrated that the spontaneous phase separation was also possible to occur in a single solvent, ${ }^{27}$ where Janus Au NPs $(d \approx$ $2 \mathrm{~nm}$ ) were successfully synthesized in toluene, based on the balance between the enthalpy of phase separation and conformational entropy between the two ligands of hexadecane-1-thiol and $1,1^{\prime}, 4^{\prime}, 1^{\prime \prime}$-terphenyl-4-thiol. In this study, spontaneous phase separation of capping ligands was also noticed to occur on the Au NPs of the interfacial reaction product between chloro(triphenyl)phosphine gold $\left(\mathrm{Au}\left(\mathrm{PPh}_{3}\right) \mathrm{Cl}\right)$ in toluene and tetrakis(hydroxymethyl)-phosphonium chloride (THPC) in alkaline solution, and the large toluene/water emulsion interface was used to synthesize ultrafine amphiphilic Janus Au NPs in batch, followed with phase inversion by adding excess toluene, leading to the batch production with a yielding rate of up to $93.3 \%$ at low cost. In addition, the Janus Au NPs are stable in colloidal state, and allow further functionalization for the possible applications on targeting drug delivery, tumor imaging and biphasic catalysis.

\section{Experimental}

\subsection{Materials and chemicals}

Gold wire (99.99\%, $d=0.5 \mathrm{~mm})$, triphenylphosphine $\left(\mathrm{PPh}_{3}, \mathrm{CP}\right)$ and toluene $(99.5 \%, \mathrm{AR})$ were from Sinopharm Chemical Reagent Co. Ltd., China. Acetonitrile $\left(\mathrm{CH}_{3} \mathrm{CN}, 99.5 \%\right.$, AR), ether (99.8\%, AR), dichloromethane $\left(\mathrm{CH}_{2} \mathrm{Cl}_{2}, 99.5 \%, \mathrm{AR}\right)$, acetone (99.5\%, AR), pentane (99\%, AR), dimethyl formamide (DMF, 99.5\%, AR), hydrochloric acid ( $\mathrm{HCl}, 36-38 \%, \mathrm{AR})$ and sodium hydroxide ( $\mathrm{NaOH}, 96 \%$, AR) were purchased from Shantou Xilong Chemicals Co. Ltd., China. Tetrakis(hydroxymethyl) phosphonium chloride (THPC, CP, 80\%) was from Tokyo Chemical Industry Co. Ltd., Japan. Deionized water (18.2 M $\Omega$ $\mathrm{cm}$ ) was employed to prepare the aqueous solutions in the experiments.

Chloro(triphenyl)phosphine gold $\left(\mathrm{Au}\left(\mathrm{PPh}_{3}\right) \mathrm{Cl}\right)$ was synthesized electrochemically following a method described by Huang et al. ${ }^{28}$ Typically, $0.95 \mathrm{~mL}$ of $\mathrm{HCl}$ was added dropwise into $15 \mathrm{~mL}$ $\mathrm{CH}_{3} \mathrm{CN}$ in a vial, followed with the dissolution of $0.092 \mathrm{~g} \mathrm{PPh}_{3}$. $\mathrm{Au}$ wire and platinum plate served as the anode and cathode, respectively. White deposit was produced on the bottom when a voltage of $2.0 \mathrm{~V}$ was applied for $6 \mathrm{~h}$, which was filtered and rinsed with ether till it appeared pure white. After drying at $60{ }^{\circ} \mathrm{C}$, the white powders were dissolved again in $1.5 \mathrm{~mL}$ of $\mathrm{CH}_{2} \mathrm{Cl}_{2}$, and re-crystallization was carried out at $-10{ }^{\circ} \mathrm{C}$ as $10 \mathrm{~mL}$ of pentane was added. The crystals were again rinsed with pentane and dried at $60{ }^{\circ} \mathrm{C}$, leading to the $\mathrm{Au}\left(\mathrm{PPh}_{3}\right) \mathrm{Cl}$ powders.

\subsection{Synthesis of amphiphilic Janus Au NPs}

$50 \mathrm{~mL}$ of $1.5 \mathrm{mM} \mathrm{Au}\left(\mathrm{PPh}_{3}\right) \mathrm{Cl}$ toluene solution and $80 \mathrm{~mL}$ of $31.25 \mathrm{mM} \mathrm{NaOH}$ solution were mixed with an emulsifying mixer in an Erlenmeyer flask at a rate of $4000 \mathrm{rpm}$, followed with the dropwise injection of $1.65 \mathrm{~mL}$ of $50 \mathrm{mM}$ THPC solution to trigger the toluene-in-water emulsion reaction. After $3 \mathrm{~h}$ of reaction, additional $50 \mathrm{~mL}$ of toluene was injected into the flask with stirring for phase inversion, and the water-in-toluene emulsion reaction was fulfilled after another $2 \mathrm{~h}$. Then, the emulsion mixture was removed in a separatory funnel and kept still overnight, where the product at the toluene/water interface was collected, and then rinsed by centrifuging with acetone and deionized water for three times, respectively, resulting in yellowish powders after freeze drying. Colloids of the Au NPs in the emulsion reaction product were prepared by ultrasonic dispersion in DMF, which were available for further characterizations.

\subsection{Analysis of $\mathrm{Au}\left(\mathrm{PPh}_{3}\right) \mathrm{Cl}$ concentration in toluene}

The reduction rate from $\mathrm{Au}\left(\mathrm{PPh}_{3}\right) \mathrm{Cl}$ to amphiphilic Janus $\mathrm{Au}$ NPs in the emulsion reaction was calculated by the following equation:

$$
R=\frac{C_{\mathrm{i}}-C_{\mathrm{f}}}{C_{\mathrm{i}}}
$$

where $C_{\mathrm{i}}$ and $C_{\mathrm{f}}$ are the initial and final concentrations of $\mathrm{Au}\left(\mathrm{PPh}_{3}\right) \mathrm{Cl}$ in toluene in the emulsion reaction. In the measurement, $5 \mathrm{~mL}$ of the sample toluene solution was injected in a silica beaker $(150 \mathrm{~mL})$, which was dried on an electric hot plate to remove the toluene slowly. Then, the evaporated residual was heated at $200{ }^{\circ} \mathrm{C}$ for $0.5 \mathrm{~h}$ and calcined at $800{ }^{\circ} \mathrm{C}$ for $20 \mathrm{~min}$. The obtained yellowish residual was removed into the silica beaker, $0.1 \mathrm{~mL}$ of $10 \% \mathrm{KCl}$ solution and $10 \mathrm{~mL}$ of aqua regia were added in sequence to re-dissolve the residual, which was dried on the electric hot plate. The final residual was dissolved again with $10 \mathrm{~mL}$ aqua regia, which was diluted with deionized water in a volumetric flask $(100 \mathrm{~mL})$, which was available for the gold content analysis. The $C_{\mathrm{i}}$ and $C_{\mathrm{f}}$ were determined by an atomic absorption spectrophotometer (AAS, TAS-986F, Beijing Puxi Universal Instruments Co, Ltd.).

\subsection{Wetting property of the thin film assemblies of Au NPs}

To investigate the phase separation of the phosphine ligands, the wetting property of the Au-NP thin film assemblies were examined. On the one hand, a thin film was prepared by the static toluene/water interfacial reaction according to our previous work, ${ }^{29}$ where $8 \mathrm{~mL}$ of $31.25 \mathrm{mM} \mathrm{NaOH}$ solution and $5 \mathrm{~mL}$ of $1.5 \mathrm{mM} \mathrm{Au}\left(\mathrm{PPh}_{3}\right) \mathrm{Cl}$ toluene solution were added in turn into a vial, followed with the injection of $165 \mu \mathrm{L}$ of $50 \mathrm{mM}$ THPC solution to trigger the reaction. After $24 \mathrm{~h}$ of reaction, a yellowish thin film was formed at the toluene/water interface. On the other hand, $1.0 \mathrm{mg}$ of the emulsion reaction product was dispersed in $10 \mathrm{~mL}$ DMF by ultrasonic stirring, led to a colloid containing $0.1 \mathrm{mg} \mathrm{mL}^{-1}$ Au NPs. $3 \mathrm{~mL}$ of the colloid were spread on the water surface in a Langmuir trough (JML04C1-P, length $\times$ width $\times$ height $=21 \mathrm{~cm} \times 8 \mathrm{~cm} \times 0.8 \mathrm{~cm}$, Shanghai Zhongchen Digital Technology Co. Ltd.). Langmuir films were 
produced as the pressure of $10 \mathrm{mN} \mathrm{m}^{-1}$ was applied on the floating Au NPs.

The above thin film assemblies were collected by clean glass slides: the slide moving upstroke from the water lifted the film up, which flipped over and left the lipophilic side up; while the slide moved downstroke to press the film into the water, which also flipped over and let the hydrophilic side up. The collected films were rinsed with acetone and deionized water, respectively, and were available for contact angle measurement after drying in ambient temperature. The contact angles of water droplets on the two surfaces were measured by a contact angle analyzer (JWA360A, Xiamen Congda Smart Technology Co. Ltd.).

\subsection{Characterizations}

The morphology of the emulsion reaction product was characterized by a transmittance electron microscope (TEM, JEM-2010 JEOL, operated at $200 \mathrm{kV}$ ) and a field emission scanning electron microscope (SEM, S-4800, Hitachi, operated at $15 \mathrm{kV}$ ). UV-vis spectrophotometer (TU1901, Beijing Puxi Universal Instruments Co, Ltd.) was used to differentiate the emulsion reaction product and the Au-NP DMF colloid by the position of maximum absorbance, with a clean glass slide and a cuvette with pure DMF as reference, respectively. A Fourier transmittance infrared spectroscope (Thermo Nexus 470 FT-IR), a confocal Raman microscope (DXR, Thermo Scientific, at $532 \mathrm{~nm}$ ), a thermogravimetric analyzer (Q-500, Thermal Analysis Instruments) and an X-ray photoelectron spectroscope (XPS, AXIS ULTRA XPS, KRATOS) were employed to determine the capping ligands of the emulsion reaction product.

The nuclear Overhauser enhanced spectroscopy (NOESY) was also employed to investigate the phase separation of the ligands on the Au NPs in the emulsion reaction product. NOESY is accepted as a phase-sensitive two-dimensional NMR technique, which can differentiate the amphiphilic Janus NPs from the homogeneous counterparts by detecting the distance-dependent nuclear Overhauser effect between proton spins. In the experiment, $25 \mathrm{mg}$ of the emulsion reaction product were dispersed in $0.6 \mathrm{~mL} \mathrm{CDCl}_{3}$, whose ${ }^{1} \mathrm{H}$ and NOESY spectra were collected by an AV-400 MHz NMR Instruments (Bruker, Karlsruhe, Germany).

\section{Results and discussion}

\subsection{Morphology of the emulsion reaction product}

In our previous work, the static interfacial reaction between the $\mathrm{Au}\left(\mathrm{PPh}_{3}\right) \mathrm{Cl}$ in toluene and THPC in alkaline solution resulted in the formation of a thin film assembly of Au NPs at the interface, and the Au NPs were found to be modified with the cleavage products of the reactants, i.e. tris(hydroxymethyl)phosphine (THP), triphenylphosphine $\left(\mathrm{PPh}_{3}\right)$ and their oxides as well as small amount of $\mathrm{Au}\left(\mathrm{PPh}_{3}\right)_{x} \mathrm{Cl}(x=1$ or 2$) \cdot{ }^{29}$ In this work, the large interface area of toluene/water emulsion drops was used to prepare the Au NPs in batch, accompanied with the phase inversion from toluene-in-water to water-in-toluene emulsions by the addition of excess toluene, in order to make effective use
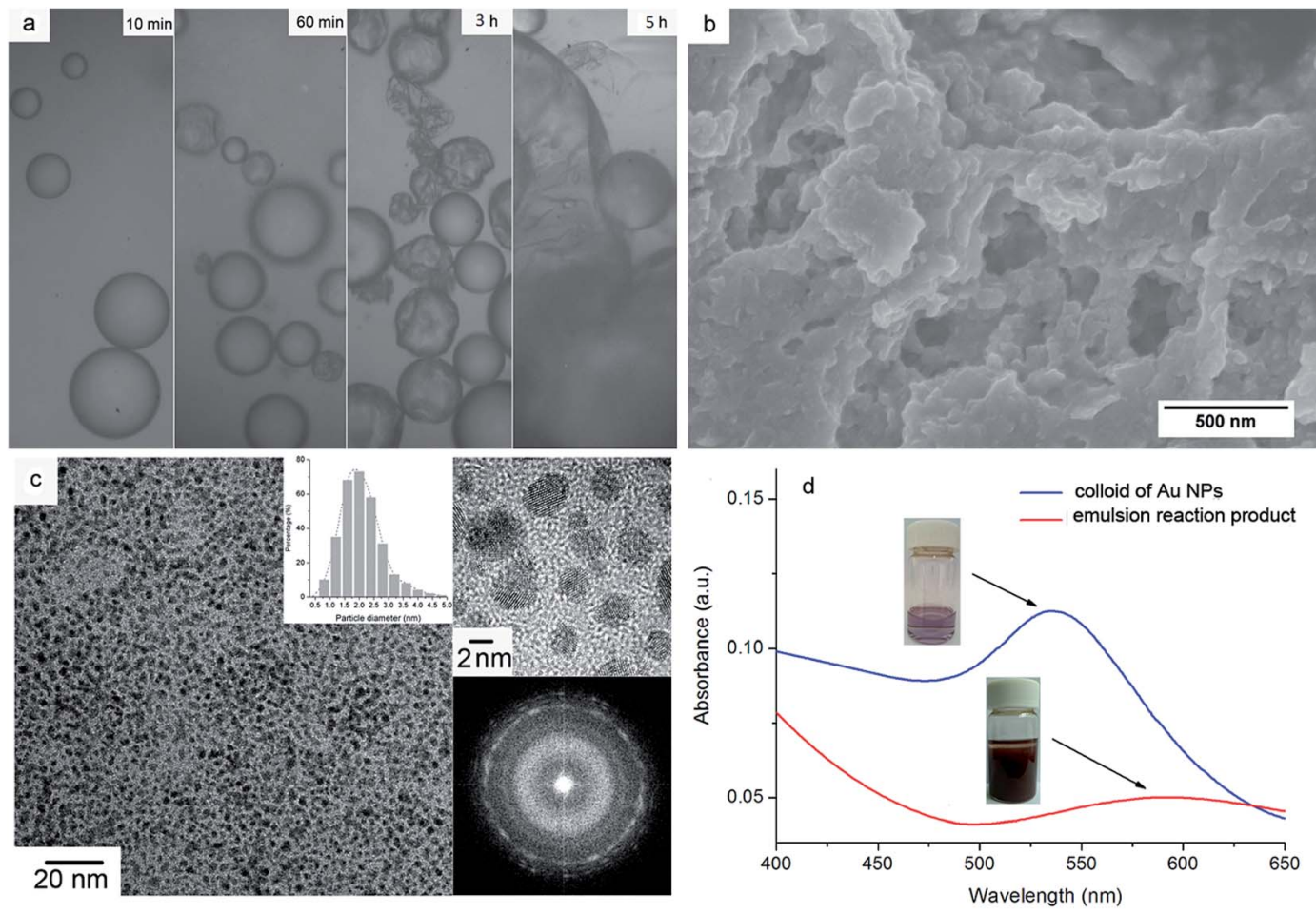

Fig. 1 Characterizations of the emulsion reaction product: (a) morphological evolution of the emulsion drops with reaction time at 10 min, $60 \mathrm{~min}, 3 \mathrm{~h}$ and $5 \mathrm{~h}$ under optical microscope; (b) SEM micrograph of the product; (c) TEM (left), HRTEM (upper right) and SAED (lower right) images of the product, and the inset shows the size distribution of Au NPs; (d) UV-vis spectra of the emulsion reaction product (lower image) and the as-dispersed Au NPs (upper image). 
of $\mathrm{Au}\left(\mathrm{PPh}_{3}\right) \mathrm{Cl}$. The analysis of atomic absorption spectroscopy shows that the initial and final concentrations of $\mathrm{Au}\left(\mathrm{PPh}_{3}\right) \mathrm{Cl}$ in toluene were $1.5 \mathrm{mmol} \mathrm{L}^{-1}$ and $0.1 \mathrm{mmol} \mathrm{L}^{-1}$, respectively, i.e. 93.3\% of $\mathrm{Au}\left(\mathrm{PPh}_{3}\right) \mathrm{Cl}$ was reduced in the emulsion reaction.

Fig. 1a shows the morphological evolution of emulsion droplets during the reaction under optical microscope: at the first $10 \mathrm{~min}$ of emulsion reaction, the droplets appear pretty round, but at $60 \mathrm{~min}$ some of them present with "wrinkled" surfaces, indicative of the formation of Au-NP thin film assemblies at the emulsion interfaces, which encapsulate the droplets in the case that some of the inner liquid is gone under the strong stirring. The lost liquid may coalesce to form new toluene-in-water emulsion droplets by stirring, so more deformed micellar assemblies are observed at $3 \mathrm{~h}$ of reaction. After the addition of excess toluene, different sized droplets and thin film fragments are seen in the picture at $5 \mathrm{~h}$ of reaction, indicative of the breakage of the films covering the toluene-in-water emulsion droplets, as well as the formation and coalescence of the Au-NP films on the water-in-toluene emulsion droplets.

Fig. 1b shows the SEM micrograph of the reaction product, which is composed of film fragments produced by the dynamic
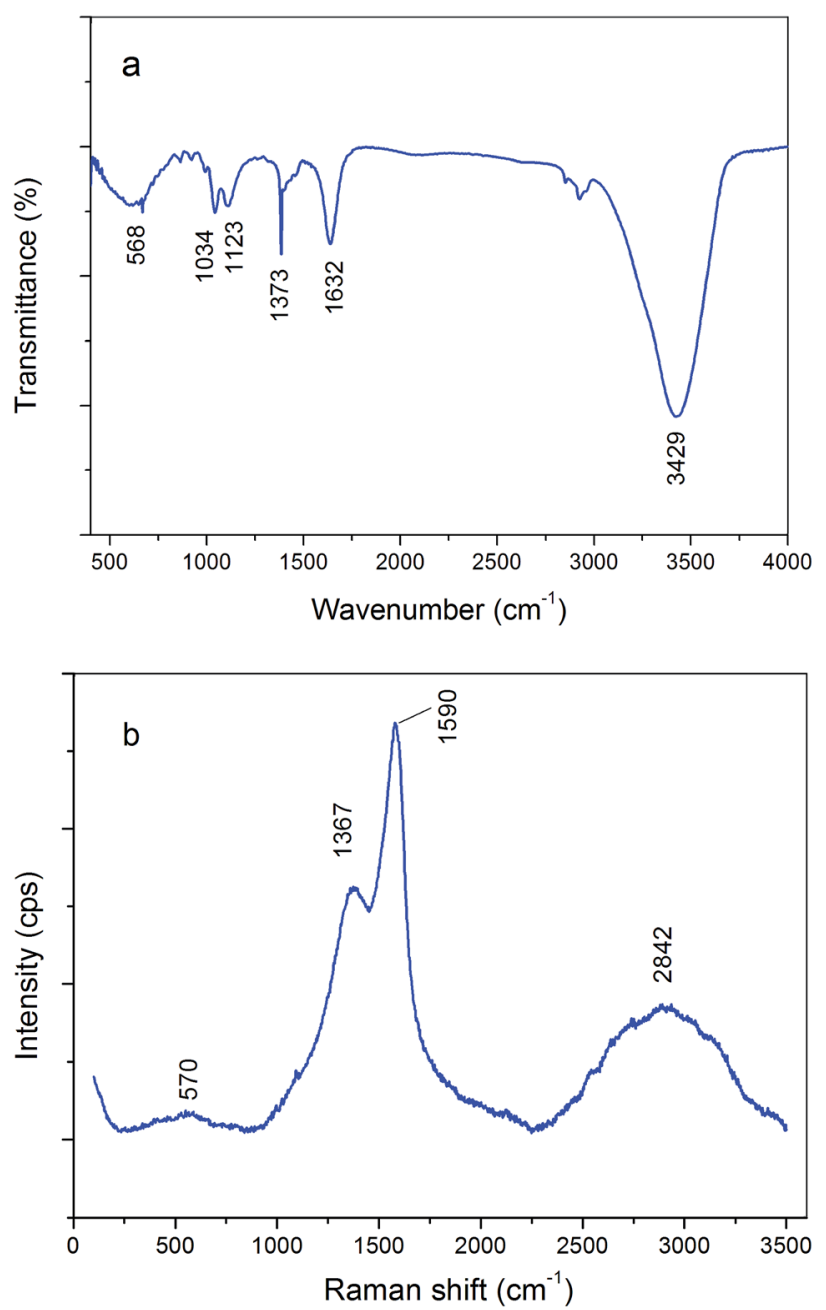

Fig. 2 FT-IR (a) and Raman (b) analyses of the emulsion reaction product. stirring and phase inversion. As the product is further enlarged in the TEM image (Fig. 1c), the film fragments are actually consisted of regularly self-assembled Au NPs in an average diameter of $2.1 \pm 0.6 \mathrm{~nm}(N=307$, shown in the inset). The HRTEM and the select area electron diffraction (SAED) displayed in the upper and lower right of Fig. 1c demonstrate that the Au NPs are in form of nanocrystals.

Fig. 1d presents the UV-vis spectra of the emulsion reaction product and its dispersion in DMF, in which the ultrasonic dispersion in DMF manifests a strong resonance peak at $538 \mathrm{~nm}$ corresponding to the absorption of colloidal Au NPs. In comparison, the emulsion reaction product presents a wide band at $c a$. $580 \mathrm{~nm}$, and the red shift of absorbance is associated with the dipolar-dipolar interaction between the Au NPs in the thin film assembly, in line with previous literature. ${ }^{29,30}$ It was also noticed that the dispersibility of the emulsion reaction product relied heavily on the property of organic solvents: the emulsion reaction product could be dispersed in chloroform, THF and DMF, but in acetone or ethanol no peak shift was examined (not shown).

\subsection{Composition of the capping ligands}

Fig. 2a is the FT-IR spectrum of the emulsion reaction product. The band at $3429 \mathrm{~cm}^{-1}$ can be assigned to the $\mathrm{O}-\mathrm{H}$ stretch, and the absorbance at $1632 \mathrm{~cm}^{-1}$ corresponds to the stretching of benzene ring in aromatic compounds. The peak at $1373 \mathrm{~cm}^{-1}$ is probably originated from the deformation of $\mathrm{P}=\mathrm{O}$ stretch, and the bands at $1123 \mathrm{~cm}^{-1}$ and $1034 \mathrm{~cm}^{-1}$ are likely attributed to the PAr stretch and $\mathrm{C}-\mathrm{O}$ stretch in primary aliphatic alcohols. The broad band at $568 \mathrm{~cm}^{-1}$ attributes to the in-plane and out-of-plane ring deformation of benzene derivatives. The Raman spectrum in Fig. $2 \mathrm{~b}$ exhibits four major bands. The band at $2842 \mathrm{~cm}^{-1}$ represents the $\mathrm{C}-\mathrm{H}$ antisymmetric and symmetric stretching of the $-\mathrm{CH}_{2}-$ in aliphatic compounds, and the peak at $1590 \mathrm{~cm}^{-1}$ is attributed to the benzene ring stretch in aromatic compounds. The bands at $1367 \mathrm{~cm}^{-1}$ and $570 \mathrm{~cm}^{-1}$ are likely attributed to the $\mathrm{P}=\mathrm{O}$ stretch and $\mathrm{P}-\mathrm{C}$ stretch, respectively. Hence, both the FT-IR and Raman analyses suggest the presence of the cleavage products on the as-synthesized Au NPs, i.e. tris(hydroxymethyl)phosphine (THP), triphenylphosphine $\left(\mathrm{PPh}_{3}\right)$ and their oxides.

The XPS survey was also employed to investigate the emulsion reaction product. Fig. 3 a shows the fitted peaks for the $\mathrm{C}_{1 \mathrm{~s}}$ signal at $284.8 \mathrm{eV}, 285.5 \mathrm{eV}$ and $286.6 \mathrm{eV}$, corresponding to the $\mathrm{C}-\mathrm{C}$ of benzene ring, $\mathrm{C}-\mathrm{OH}$ and $\mathrm{C}=\mathrm{O}$ bonds. For the resolved $\mathrm{O}_{1 \mathrm{~s}}$ signal, three fitted peaks are observed at $530.5 \mathrm{eV}, 531.4 \mathrm{eV}$ and $532.2 \mathrm{eV}$ in Fig. $3 \mathrm{~b}$, assigned to the groups of $\mathrm{P}=\mathrm{O}, \mathrm{C}-\mathrm{OH}$ and $\mathrm{C}=\mathrm{O}$. The fitting of the resolved $\mathrm{P}_{2 \mathrm{p}}$ peak ends up with five peaks at $130.8 \mathrm{eV}, 131.6 \mathrm{eV}, 132.2 \mathrm{eV}, 133.2 \mathrm{eV}$ and $134.4 \mathrm{eV}$ as displayed in Fig. 3c, corresponding to the composition of $\mathrm{PPh}_{3}$, THP, $\mathrm{PPh}_{3} \mathrm{O}$, THPO and $\mathrm{Au}\left(\mathrm{PPh}_{3}\right) \mathrm{Cl}$, respectively. As for the $\mathrm{Au}_{4 \mathrm{f}}$ signal, two major fitted peaks appear at $83.9 \mathrm{eV}$ and $87.6 \mathrm{eV}$ in Fig. 3d, which can be assigned to the $\mathrm{Au}_{4 \mathrm{f}_{7 / 2}}$ and $\mathrm{Au}_{4 \mathrm{f}_{5 / 2}}$ of metallic gold. A small peak at $85.0 \mathrm{eV}$ attributed to $\mathrm{Au}_{4 \mathrm{f}_{7 / 2}}{ }^{+}(<2.9$ at\%) is also present, indicative of the existence of $\mathrm{Au}\left(\mathrm{PPh}_{3}\right)_{x} \mathrm{Cl}(x$ $=1$ or 2 ), in agreement with the analysis of $\mathrm{P}_{2 \mathrm{p}}$. The possible ligand composition from XPS analysis is listed in Table 1, which demonstrates that the atomic ratio of the lipophilic molecules 

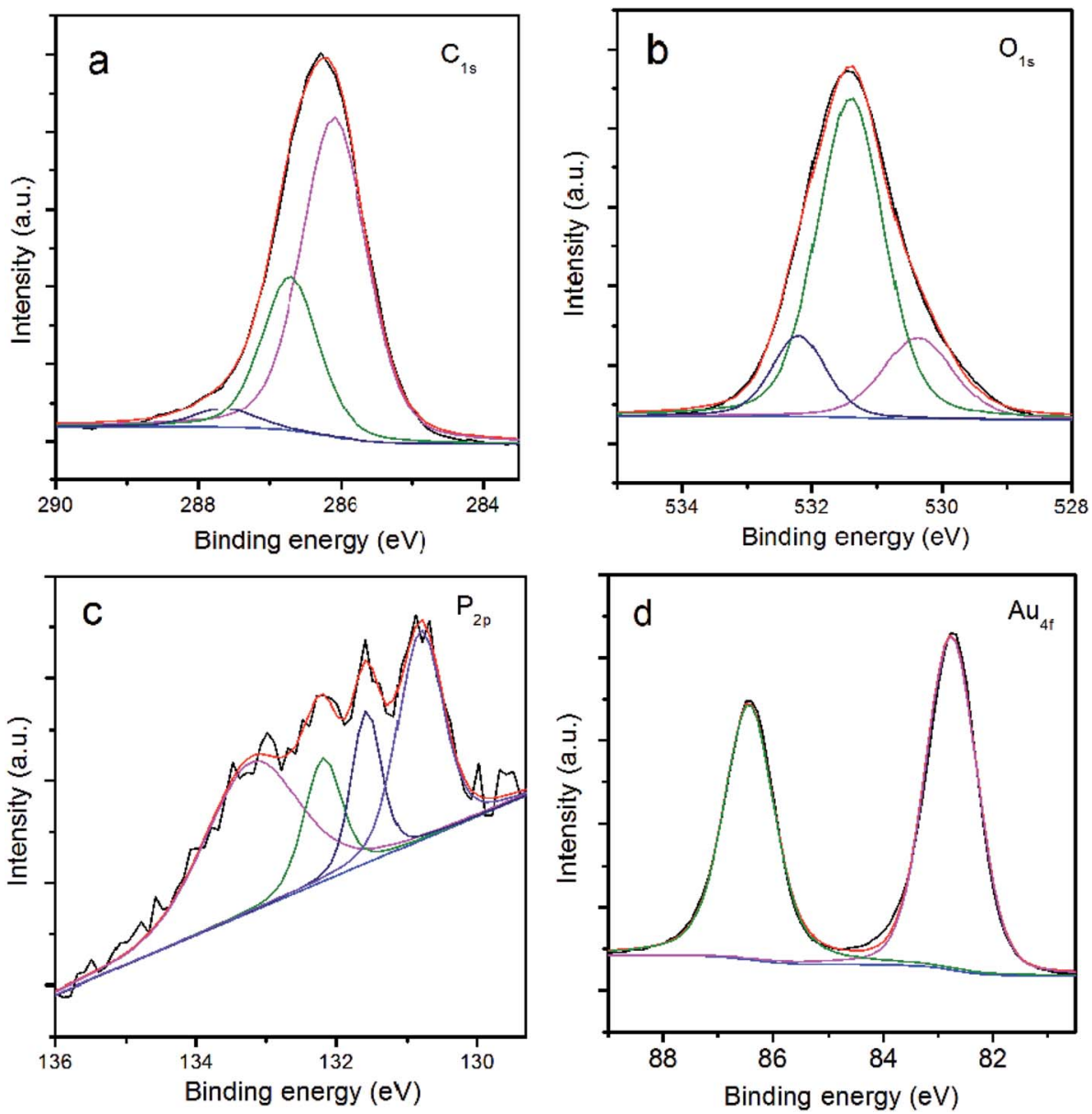

Fig. 3 XPS analysis of the emulsion reaction product: (a) fitting of $C_{1 s}$ signal; (b) fitting of $O_{1 s}$ signal; (c) fitting of $P_{2 p}$ signal; (d) fitting of $A u_{4 f}$ signal.

Table 1 XPS analysis of the emulsion reaction product

\begin{tabular}{lllll}
\hline Elements & $\begin{array}{l}\text { B. E. } \\
(\mathrm{eV})\end{array}$ & $\begin{array}{l}\text { FWHM } \\
(\mathrm{eV})\end{array}$ & $\begin{array}{l}\text { Atomic percentage } \\
(\%)\end{array}$ & $\begin{array}{l}\text { Possible } \\
\text { chemistry }\end{array}$ \\
\hline $\mathrm{C}_{1 \mathrm{~s}}$ & 284.8 & 1.19 & 84.09 & $\mathrm{C}-\mathrm{C}$ (benzene ring) \\
& 285.5 & 1.15 & 14.65 & $\mathrm{C}-\mathrm{OH}$ \\
& 286.6 & 0.89 & 1.26 & $-\mathrm{C}=\mathrm{O}$ \\
$\mathrm{O}_{1 \mathrm{~s}}$ & 530.5 & 1.38 & 21.88 & $\mathrm{O}=\mathrm{P}-$ \\
& 531.4 & 1.18 & 63.60 & $\mathrm{C}-\mathrm{OH}$ \\
& 532.2 & 0.98 & 14.52 & $-\mathrm{C}=\mathrm{O}$ \\
$\mathrm{P}_{2 \mathrm{p}}$ & 130.8 & 0.74 & 28.67 & $\mathrm{PPh}_{3}$ \\
& 131.6 & 0.5 & 14.03 & $\mathrm{THP}$ \\
& 132.2 & 0.71 & 18.07 & $\mathrm{PPh}_{3} \mathrm{O}$ \\
& 133.2 & 1.34 & 35.64 & $\mathrm{THPO}$ \\
$\mathrm{Au}_{4 \mathrm{f}}$ & 134.4 & 0.95 & 3.59 & $\left.\mathrm{PPh}_{3}\right) \mathrm{Cl}$ \\
& 83.9 & 1.02 & 53.03 & $\mathrm{Au}_{4 \mathrm{f}_{7 / 2}}{ }^{+}$ \\
$\mathrm{Au}_{4 \mathrm{f}}$ & 85.0 & 0.98 & 2.87 & $\mathrm{Au}_{4 \mathrm{f}_{5 / 2}}{ }^{\circ}$
\end{tabular}

$\left(\mathrm{PPh}_{3}\right.$ and $\left.\mathrm{PPh}_{3} \mathrm{O}\right)$ to the hydrophilic ligands (THP and THPO) is at about 0.94 .

Fig. 4 displays the thermogravimetric analyses of the emulsion reaction product. There is no visible weight loss at the temperature lower than $100{ }^{\circ} \mathrm{C}$, indicative of a dry and stable sample. A weight loss of $26 \%$ appears in the TG curve at the range from $100{ }^{\circ} \mathrm{C}$ to $200{ }^{\circ} \mathrm{C}$, where the DTG curve shows three endothermic processes probably attributing the release of incorporated solvents (toluene) and excess ligand molecules (THP, THPO, $\mathrm{PPh}_{3}$ or $\mathrm{PPh}_{3} \mathrm{O}$ ). 5.6\% of the weight is lost in the range from $200{ }^{\circ} \mathrm{C}$ to $400{ }^{\circ} \mathrm{C}$, corresponding to the thermal cleavage of THP and THPO to phosphates, and the $12.3 \%$ weight loss from $400{ }^{\circ} \mathrm{C}$ to $780^{\circ} \mathrm{C}$ is likely assigned to the degradation of $\mathrm{PPh}_{3}$ and $\mathrm{PPh}_{3} \mathrm{O}$. The atomic ratio of the lipophilic $\left(\mathrm{PPh}_{3}\right.$ and $\left.\mathrm{PPh}_{3} \mathrm{O}\right)$ to hydrophilic (THP and THPO) groups is estimated as ca. 1.1 from the pyrolytic data of thermal degradation. Both the XPS survey and TG analysis indicate that the hydrophilic and the similar amount of lipophilic ligands are present on the Au NP's surface in the emulsion reaction product.

\subsection{Distribution of the capping ligands}

NOESY is a phase-sensitive two-dimensional NMR technique, and has been employed to differentiate Janus nanoparticles from the homogeneous counterparts by detecting the distancedependent nuclear Overhauser effect between proton spins. ${ }^{22}$ As shown in Fig. 5, the ${ }^{1} \mathrm{H}$ NMR spectrum of the emulsion reaction product dispersed in $\mathrm{CDCl}_{3}$ presents five peaks, where the peaks at $0.85 \mathrm{ppm}$ and $1.27 \mathrm{ppm}$ are likely attributed to the methylene and hydroxyl protons of THP and THPO or their derivatives, and 


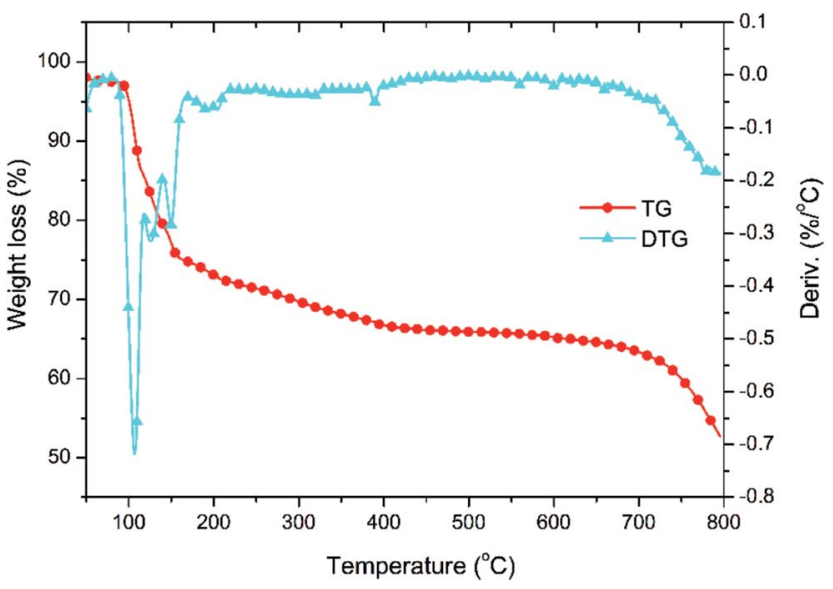

Fig. 4 Thermogravimetric (TG and DTG) analysis of the emulsion reaction product.

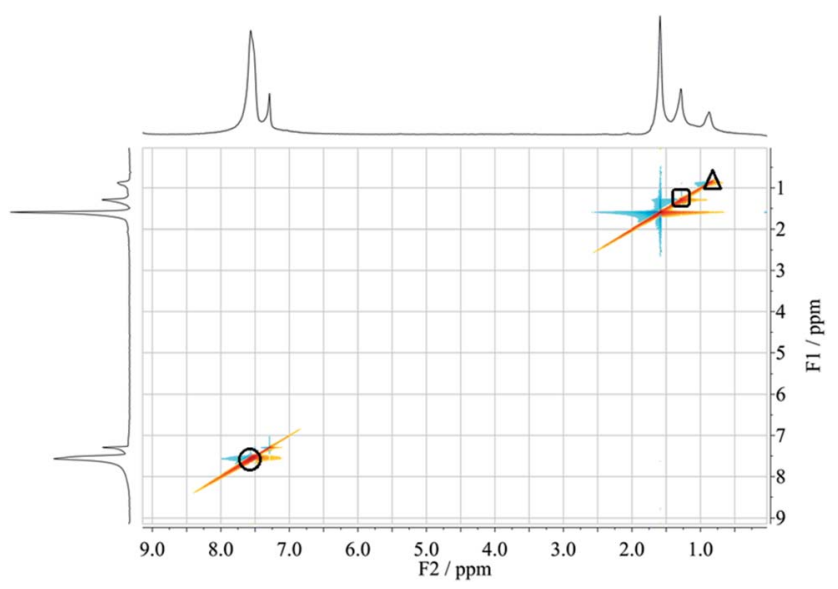

Fig. $5{ }^{1} \mathrm{H}$ NMR and NOESY analyses of the emulsion reaction product.

the strong peak at $1.56 \mathrm{ppm}$ is assigned to the proton in $\mathrm{H}_{2} \mathrm{O}$. The peak at $7.26 \mathrm{ppm}$ is corresponding to the solvent $\mathrm{CDCl}_{3}$, and the one at $7.52 \mathrm{ppm}$ is assigned to the protons in $\mathrm{PPh}_{3}$ and/ or $\mathrm{PPh}_{3} \mathrm{O}$. The diagonal profile in the NOESY spectrum in Fig. 5 indicates the interchain interactions on the Au NPs, which are arisen from the adjacent protons of the hydrophilic molecules (square and triangle) and lipophilic molecules (circle). The absence of signals in the reverse diagonal suggests that the interactions between the protons of THP/THPO and the ones of $\mathrm{PPh}_{3} / \mathrm{PPh}_{3} \mathrm{O}$ can be ignored, demonstrating that the hydrophilic (THP/THPO) and the lipophilic $\left(\mathrm{PPh}_{3} / \mathrm{PPh}_{3} \mathrm{O}\right)$ ligands actually situate on two separate compartments of the Au NPs' surface.

To further understand the phase separation on the Au NPs, the wetting properties on the two surfaces of Au-NP thin film assemblies were also tested, where two kinds of samples were used in the experiment: (1) thin films synthesized by the static toluene/water interfacial reaction with the same recipe as the emulsion reaction; (2) Langmuir re-assemblies of the as-dispersed emulsion reaction product. Fig. 6a shows the pressure-area isotherm for the formation of Langmuir re-assembly of the as-dispersed emulsion reaction product. As the colloidal Au NPs were compressed in the
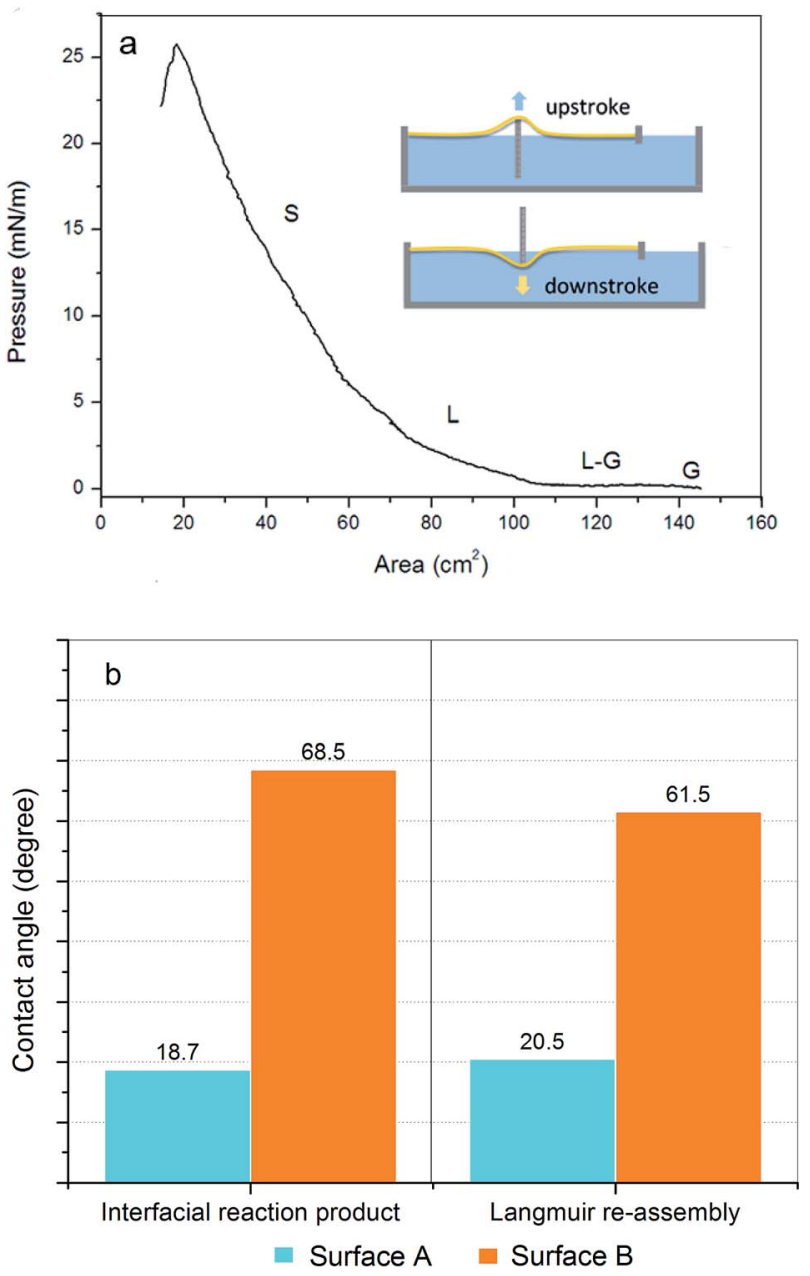

Fig. 6 Janus wettability of the Au-NP thin film assemblies: (a) Langmuir re-assembly and sample collection of the as-dispersed emulsion reaction product; (b) contact angles on the two surfaces of the thin film by toluene/water interfacial reaction and the Langmuir reassembly of the as-dispersed emulsion reaction product.

Langmuir trough, the re-assembly of the Au NPs was prompted on the water surface, during which the structure of the floating $\mathrm{Au}$ NPs varied from the gaseous (G) phase, transition (gas-liquid, LG) state, liquid (L) phase to the solid phase (S, i.e. Langmuir film) as marked in the graph, as the pressure increased from $6.8 \mathrm{mN}$ $\mathrm{m}^{-1}$ to $25.8 \mathrm{mN} \mathrm{m}^{-1}$. Hence, the Langmuir re-assembly for contact angle measurement was prepared at the pressure of 10 $\mathrm{mN} \mathrm{m}^{-1}$. The inset of Fig. 6a shows the way of collecting samples by the upstroke or downstroke movement of glass slides, which was also applied for collecting the films by the toluene/water interfacial reaction. In the latter case, the film located at the toluene/water interface, and the collection had to pass through the upper toluene layer in the system.

Fig. 6b illustrates that the contact angles on the two surfaces of the film by the interfacial reaction are determined as $68.5^{\circ}$ and $18.7^{\circ}$, and the ones for the Langmuir re-assembly are $61.5^{\circ}$ and $20.5^{\circ}$, respectively. The Janus wettability on the two surfaces of the thin film by the toluene/water interfacial reaction suggests that spontaneous phase separation of capping ligands occurred with the formation of the Au NPs at the toluene/water interface, 
owing to the constraint of the immiscible liquid/liquid interface, the biphasic supply and different affinity of ligand molecules. The Langmuir re-assembly of the as-dispersed Au NPs also present different wettability on the two surfaces, indicating that the $\mathrm{Au}$ NPs of the emulsion reaction product are still Janus amphiphiles in the colloidal state, which allow further functionalization for the prospective applications on targeting drug delivery, tumor imaging and biphasic catalysis. The ultrafine amphiphilic Janus Au NPs can be safely stored at ambient temperature, and the one-pot synthesis allows scalable production of amphiphilic Janus Au NPs at low cost.

\section{Conclusion}

Ultrafine amphiphilic Janus Au NPs were synthesized in batch by the emulsion reaction between $\mathrm{Au}\left(\mathrm{PPh}_{3}\right) \mathrm{Cl}$ in toluene and THPC in alkaline solution, followed with phase inversion to make effective use of $\mathrm{Au}\left(\mathrm{PPh}_{3}\right) \mathrm{Cl}$, led to a facile and scalable approach at a yielding rate of up to $93.3 \%$. TEM and UV-vis analyses indicate that the product are composed of Au nanocrystals with average diameter of $2.1 \mathrm{~nm}$, and can be dispersed in organic solvents like DMF, THF and chloroform. FT-IR, Raman, XPS and TG analyses demonstrate that the Au NPs in the product are protected with lipophilic ligands $\left(\mathrm{PPh}_{3}\right.$ and $\left.\mathrm{PPh}_{3} \mathrm{O}\right)$ and the similar amount of hydrophilic molecules (THP and THPO). The NOESY experiment further demonstrate that the capping ligands of the individual $\mathrm{Au}$ NPs in the product are separated into the hydrophilic and lipophilic compartments, and the surface chemistry keeps stable for the as-dispersed Au NPs in DMF. The facile batch production of the amphiphilic Janus Au NPs allows prospective applications on targeting drug delivery, tumor imaging and biphasic catalysis at low cost. More efforts are under way on encapsulating anticancer drugs and tailoring the morphology of the Au-NP microcapsules.

\section{Conflicts of interest}

There are no conflicts to declare.

\section{Acknowledgements}

We grateful acknowledge the support from the National Natural Science Foundation of China (No. 21163004), Guangxi Natural Science Foundation (No. 2016GXNSFAA380107 and 2013 GXNSFAA019029), and the funding from the Collaborative Center for Exploration of Hidden Nonferrous Metal Deposits and Development of New Materials in Guangxi, and Guangxi Key Laboratory of Universities for Clean Metallurgy and Comprehensive Utilization of Nonferrous Metal Resources.

\section{References}

1 G. De Crozals, R. Bonnet, C. Farre and C. Chaix, Nano Today, 2016, 11, 435-463.

2 K. M. Harkness, B. N. Turner, A. C. Agrawal, Y. Zhang, J. A. McLean and D. E. Cliffel, Nanoscale, 2012, 4, 3843-3851.

3 I. Brigger, C. Dubernet and P. Couvreur, Adv. Drug Delivery Rev., 2002, 54, 631-651.
4 M. Srinivasan, M. Rajabi and S. A. Mousa, Nanomaterials, 2015, 5, 1690-1703.

5 T. Dreifuss, O. Betzer, M. Shilo, A. Popovtzer, M. Motiei and R. Popovtzer, Nanoscale, 2015, 7, 15175-15184.

6 P. P. Yang, Y. G. Zhai, G. B. Qi, Y. X. Lin, Q. Luo, Y. Yang, A. P. Xu, C. Yang, Y. S. Li, L. Wang and H. Wang, Small, 2016, 12, 5423-5430.

7 L. Mocan, C. Matea, F. A. Tabaran, O. Mosteanu, T. Pop, T. Mocan and C. Iancu, Int. J. Nanomed., 2015, 10, 5435-5445.

8 A. J. Mieszawska, W. J. Mulder, Z. A. Fayad and D. P. Cormode, Mol. Pharmaceutics, 2013, 10, 831-847.

9 M. X. Yu and J. Zheng, ACS Nano, 2015, 9, 6655-6674.

10 H. Cao, Y. Yang, X. Chen and Z. Shao, Nanoscale, 2016, 8, 6754-6760.

11 N. Amreddy, R. Muralidharan, A. Babu, M. Mehta, E. V. Johnson, Y. D. Zhao, A. Munshi and R. Ramesh, Int. J. Nanomed., 2015, 10, 6773-6788.

12 X. Niu, F. Ran, L. Chen, G. J.-E. Lu, P. Hu, C. P. Deming, Y. Peng, M. D. Rojas-Andrade and S. Chen, Langmuir, 2016, 32, 4297-4304.

13 A. G. Skirtach, A. Munoz Javier, O. Kreft, K. Kohler, A. Piera Alberola, H. Mohwald, W. J. Parak and G. B. Sukhorukov, Angew. Chem., Int. Ed. Engl., 2006, 45, 4612-4617.

14 S. Rana, A. Bajaj, R. Mout and V. M. Rotello, Adv. Drug Delivery Rev., 2012, 64, 200-216.

15 W. P. Savarimuthu, P. Gananathan, A. P. Rao, E. Manickam and G. Singaravelu, J. Nanosci. Nanotechnol., 2015, 15, 5577-5584.

16 M. Raoof, S. J. Corr, W. D. Kaluarachchi, K. L. Massey, K. Briggs, C. H. Zhu, M. A. Cheney, L. J. Wilson and S. A. Curley, Nanotechnology, Biology and Medicine, 2012, 8, 1096-1105.

17 S. Aryal, S. Pilla and S. Gong, J. Nanosci. Nanotechnol., 2009, 9, 5701-5708.

18 Y. Liu, J. J. Yin and Z. H. Nie, Nano Res., 2014, 7, 1719-1730.

19 H. Mitomo, K. Niikura and K. Ijiro, Kobunshi Ronbunshu, 2016, 73, 147-156.

20 A. Boker, J. He, T. Emrick and T. P. Russell, Soft Matter, 2007, 3, 1231-1248.

21 B. P. Binks and P. D. I. Fletcher, Langmuir, 2001, 17, 4708-4710. 22 S. Pradhan, L. Brown, J. Konopelski and S. Chen, J. Nanopart. Res., 2009, 11, 1895-1903.

23 S. Pradhan, L. Xu and S. Chen, Adv. Funct. Mater., 2007, 17, 2385-2392.

24 Q. A. Xu, X. W. Kang, R. A. Bogomolni and S. W. Chen, Langmuir, 2010, 26, 14923-14928.

25 D. M. Andala, S. H. R. Shin, H. Y. Lee and K. J. M. Bishop, ACS Nano, 2012, 6, 1044-1050.

26 K. Luo, Y. Xiang, H. Wang, L. Xiang and Z. Luo, J. Mater. Sci. Technol., 2016, 32, 733-737.

27 S. Kim, T.-H. Kim, J. Huh, J. Bang and S.-H. Choi, ACS Macro Lett., 2015, 4, 417-421.

28 T. Huang, K. Luo, H. Huang, X. Li and Q. Zeng, Precious Met., 2012, 33, 14-17, (in Chinese).

29 K. Luo, S. L. Schroeder and R. A. Dryfe, Chem. Mater., 2009, 21, 4172-4183.

30 C. N. R. Rao, G. U. Kulkarni, P. J. Thomas, V. V. Agrawal and P. Saravanan, J. Phys. Chem. B, 2003, 107, 7391-7395. 